\title{
Simulation-Based Learning, an Essential Tool for Control Process in Food Engineering Education
}

\author{
Anca, ŞIPOŞ \\ "Lucian Blaga" University of Sibiu, Sibiu, Romania \\ anca.sipos@ulbsibiu.ro \\ Mariana Liliana, PĂCAL Ă \\ "Lucian Blaga" University of Sibiu, Sibiu, Romania \\ mariana.pacala@ulbsibiu.ro
}

\begin{abstract}
Simulation-based learning has become an essential tool for food engineers in education and industry. The students from food engineering higher education usually have difficulties to understand abstract concepts of the process control, to make links among microbiology, biochemistry and automation of the technological process from food industry. The present paper describes a methodology for teaching the process control by developing a control level process using simulation-based learning. The used of this metode highlighted that the students developed competence toward "thinking like a scientist", developed argumentation and critical decision-making skills and reinforced research-planning and experimental design skills.
\end{abstract}

Keywords: simulation-based learning, virtual technological system, teaching process control

\section{INTRODUCTION}

Recently, a worldwide emphasis for global competitiveness in the 21 st century has been to educate individuals in science, technology, engineering and computers technology to produce a competitive future workforce (Sevgi, A.G., Aysegul T.C., Elif, S.K., \& Betul, E.K., 2018). However, it was revealed that employers in industry have difficulty in finding such employees who have the capability of identifying, adapting, and utilizing scientific and technological knowledge for developing unique technologies (Kennedy, T., \& Odell, M., 2014).

A new, promising branch of science was born at a specific meeting point: bioengineering. Bioengineering especially has developed in connection with biotransformation processes (biosynthesis-biodegradation), in order to obtain antibiotics, enzymes, vitamins, amino acids, organic acids, bicarbonates, biopolymers, as a result of the cooperation among microbiologist, biochemist, chemical, food industry and mechanical engineer, process control engineer and computer engineer, in a domain which is called Microbial Engineering and Biochemical Engineering (Jordão, A.M., \& Cosme, F., 2018).

The students from food engineering higher education usually have difficulties to understand abstract concepts of the process control, to make links among microbiology, biochemistry and automation of the technological process from food industry. Thus, the process control teaching became an integral and indispensable part of the active assimilation of theoretical and practical knowledge.

A new methods for engineering higher education is the inquiry-based approach or simulation-based learning. Inquiry-based learning can be defined as a process of discovering new causal relations, with the learner formulating hypotheses and testing them by conducting experiments and/or making observations (Belton, D.J., 2016). Simulation-based learning has become an essential tool for food engineers in education and industry. Various studies examining the teaching and learning of process 
simulation are available, although no clear theoretical frameworks for process simulation pedagogy currently exist. Simulation-based learning offers the students many advantages: performing individual and team student work, originality and practical usefulness, interdisciplinary fields.

Inquiry-based learning is a central form of teaching and learning in engineering higher education. It is an activity-oriented, student-centered and collaborative learning approach that has gained more and more prominence in recent years (Kaiser, I., Mayer, J., \& Malai, D., 2018). In inquiry-based learning students become actively involved in knowledge construction by following an idealized hypotheticodeductive method. Inquiry-based learning courses can take different forms, but have two principles in common: deep active engagement and opportunities to collaborate.

The work presented here describes a methodology for teaching the process control by developing a control level process using inquiry-based approach or simulation-based learning. Three laboratories have deal with the construction and simulation of the level control process. The students were grouped in three teams and each team realised the feedback system of the reservoir's level in MATLABSimulink. Tutor supervised the process construction and intervened only on demand. For tuning the controller's parameters has been used the method of the stability limit, the Ziegler-Nichols' method. At the end, the students' teams discussed and analysed the results.

The proposed method covers different pedagogical purposes:

a. to develop competence toward "thinking like a scientist";

b. to promote argumentation skills and critical decision making;

c. to improve students' research-planning and experimental-design skills.

\section{METHOD FRAMEWORK}

\subsection{Modelling}

The main equation of the mathematical model is the total mass balances:

$$
A \rho \cdot \frac{d h}{d t}=F_{i} \cdot \rho_{i}-F_{e} \cdot \rho_{e}
$$

where $h$ is the level of the liquid from the reservoir, $A$ the transversal section area of the reservoir, $F_{i}$ and $F_{e}$ represent the feeding flow and relief flow and $\rho_{i}$ respectively $\rho_{e}$ are the densities of the liquid in the feeding and relief flows. Because the process is taking place in isothermal conditions, can be considerate that $\rho_{i}=\rho_{e}=\rho$.

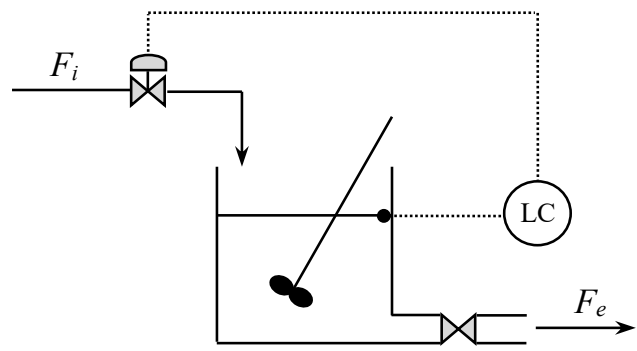

Figure 1. The level control in a reservoir

Under the influence of the liquid level variation the relief flow is inconstant. It will be written the Bernoulli equation for the relief flow of the reservoir (Pavlov, C.F., Romankov, P.G., \& Noscov, A.A., 1981):

$$
\rho g(h+H)=\frac{v^{2} \rho}{2}\left(1+\frac{\lambda L}{d_{c}}+\sum \xi\right)
$$


where $H$ is the level difference between the reservoir bottom and the relief point, $\lambda$ is the friction coefficient on the pipe, $L$ is the pipe length, $d_{c}$ is the inside pipe diameter and $\sum \xi$ represents the sum of the local resistance of the fixtures assembled on the pipe. Using this equation it can be written:

$$
F_{c}=v \cdot A_{c}=A_{c} \cdot \sqrt{\frac{2 g(h+H)}{1+\frac{\lambda L}{d_{c}}+\sum \xi}}
$$

where $A_{c}$ is the transversal section area of the pipe.

The friction coefficient $\lambda$ for the steel pipes has the following equations:

- for the laminar flow - $R e \leq 23000$ :

$$
\lambda=\frac{64}{R e}
$$

- for the turbulent flow - $R e \geq 2300$ :

$$
\lambda=0,014+\frac{1,056}{R e^{0,42}}
$$

equations where the $R e$ criterion is calculated with the equation:

$$
\operatorname{Re}=\frac{v \rho d_{c}}{\eta}
$$

where $\eta$ is the liquid viscosity.

For the mathematical model has been build a S-function in MATLAB in order to simulate the dynamic behaviour of the reservoir.

\subsection{Simulation}

In MATLAB-Simulink computing software the feedback control system of the reservoir's level has been realised by the each group of students. Then, has been used the method of the stability limit, the Ziegler-Nichols' method, for tuning the controller's parameters (Agachi, P.S., \& Cristea, M.V., 2014). The process has been brought to instability with the method of successive trials in order to obtain the oscillation value of the gain factor $K_{u}$ (or oscillation value of the proportional band $P B_{u}$ ) and the ultimate period $P_{u}$.

The block diagram of the process level control is presented in figure 2.

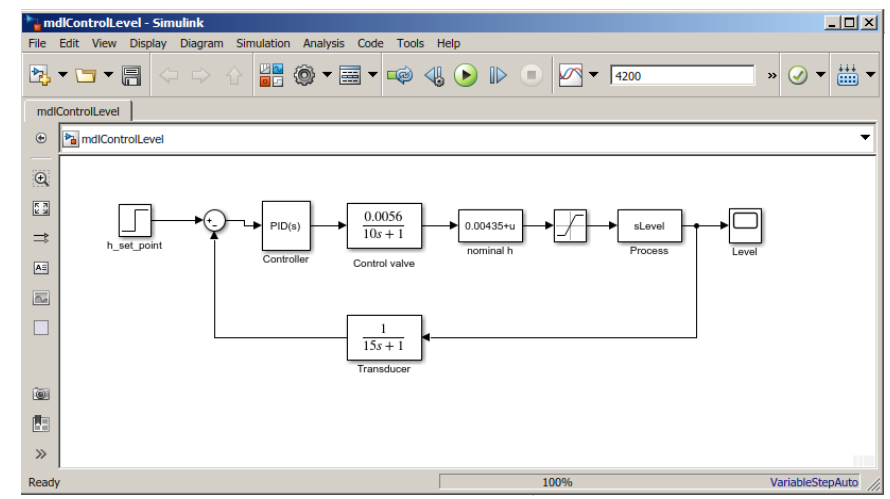

Figure 2: The Simulink block diagrama of the reservoire level control

With the values of $K_{u}$ and $P_{u}$ experimentally determined, Ziegler and Nichols proposed the optimal controller parameters given in table 1. 
Table 1: Optimal controller parameters proposed by Ziegler and Nichols [7]

\begin{tabular}{|c|c|c|c|}
\hline \multirow{2}{*}{$\begin{array}{c}\text { Optimal } \\
\text { controller } \\
\text { parameter }\end{array}$} & \multicolumn{3}{|c|}{ Controller structure } \\
\cline { 2 - 4 } & $\boldsymbol{P}$ & $\boldsymbol{P I}$ & $\boldsymbol{P I D}$ \\
\hline $\boldsymbol{P B}[\%]$ & $2 P B_{u}$ & $2.2 P B_{u}$ & $1.7 P B_{u}$ \\
\hline $\boldsymbol{T}_{\boldsymbol{i}}[\mathrm{min}]$ & - & $0.83 P_{u}$ & $0.5 P_{u}$ \\
\hline $\boldsymbol{T}_{\boldsymbol{d}}[\mathrm{min}]$ & - & - & $0.12 P_{u}$ \\
\hline
\end{tabular}

The students groups have been simulated three cases of the level control: the first group for the initial step perturbation of level form $3 \mathrm{~m}$ to $1.5 \mathrm{~m}$, the second group from $3 \mathrm{~m}$ to $5 \mathrm{~m}$ and the third from 3 $\mathrm{m}$ to $2.5 \mathrm{~m}$. Each group has established the optimal parameters for the adequate controller in accordance with Ziegler-Nichols' method.

\section{RESULTS AND DISCUSSION}

With the method of successive trials the process has been brought to instability. The students' groups have been simulated the process by increasing the gain factor $K_{u}$ of the controller until has been reached the limit of the stability. In figure 3 is presented, in the left, the variation in time of the level with 80 value of the gain factor and in the right is the level variation with 100 value of the gain factor. It can be observed that in the second case the process presented permanent oscillations with the same amplitude. Then, the students have been measured the ultimate period as is shown in figure 4 .
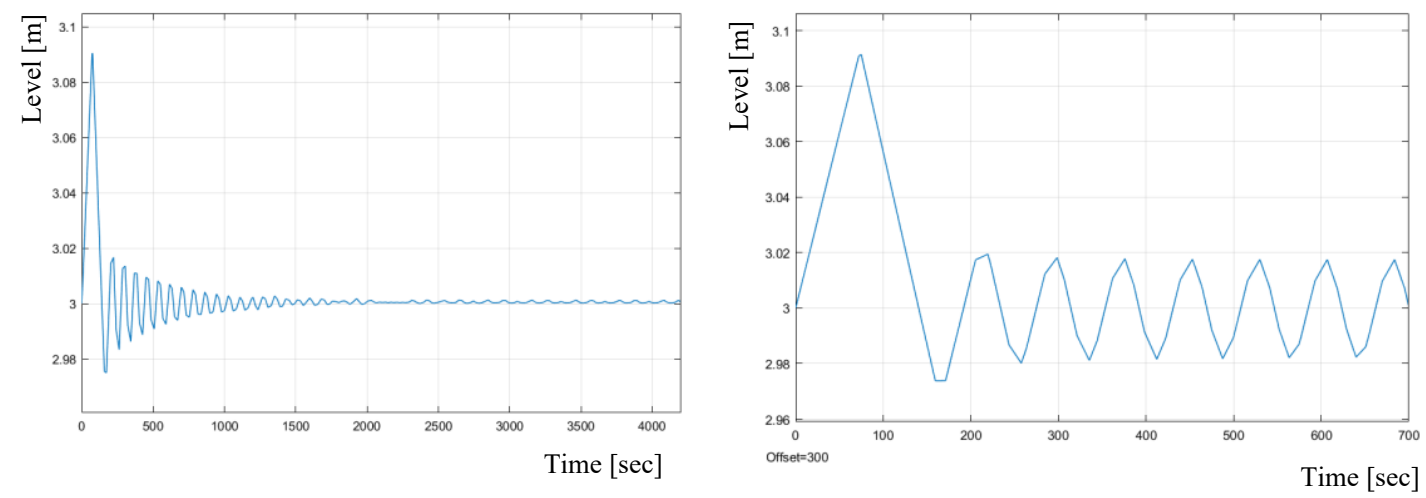

Figure 3: The process response at the increasing of the gain factor

The optimal settings of the controller, according to Ziegler and Nichols are given in table 2 . 


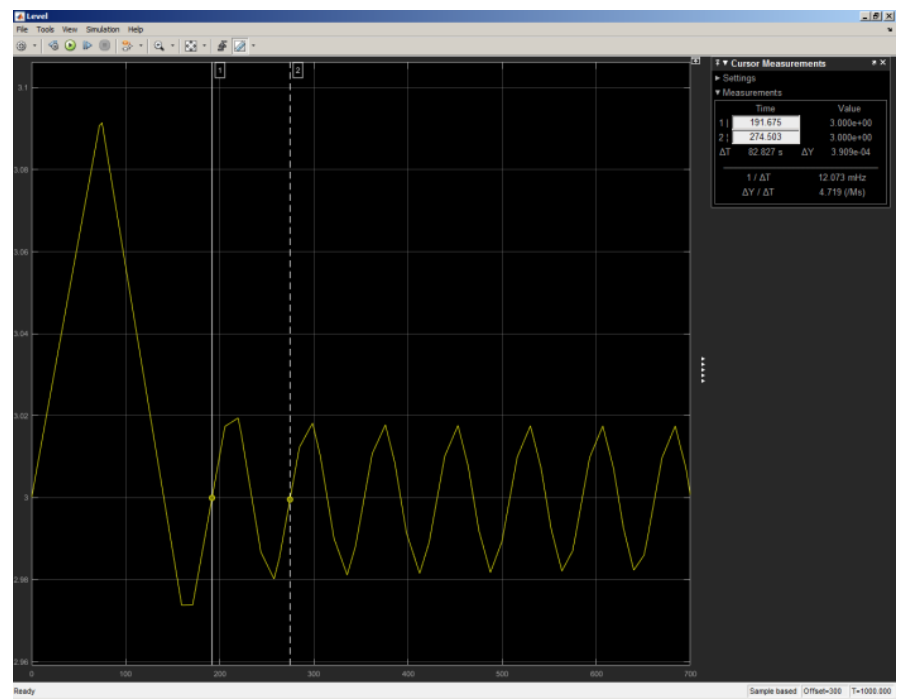

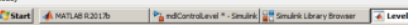

Figure 4: The ultimate period calculation

Table 2: The optimal controller settings in the fermentation process control loop

\begin{tabular}{|c|c|c|c|}
\hline \multirow{2}{*}{$\begin{array}{c}\text { Optimal } \\
\text { controller } \\
\text { parameter }\end{array}$} & $\boldsymbol{3}$ Controller structure \\
\cline { 2 - 4 } & $\boldsymbol{P}$ & $\boldsymbol{P I}$ & $\boldsymbol{P I D}$ \\
\hline$K_{u}$ & 50 & 45.45 & 58.82 \\
\hline $\boldsymbol{T}_{\boldsymbol{i}}[\mathrm{se}]$ & - & 68 & 41 \\
\hline $\boldsymbol{T}_{\boldsymbol{d}}[\mathrm{sec}]$ & - & - & 9.84 \\
\hline
\end{tabular}

In figure 5 are given the behavior of the control loop for the $P, P I$ and $P I D$ controllers considering the table 2 , in two cases of the lavel step perturbation.

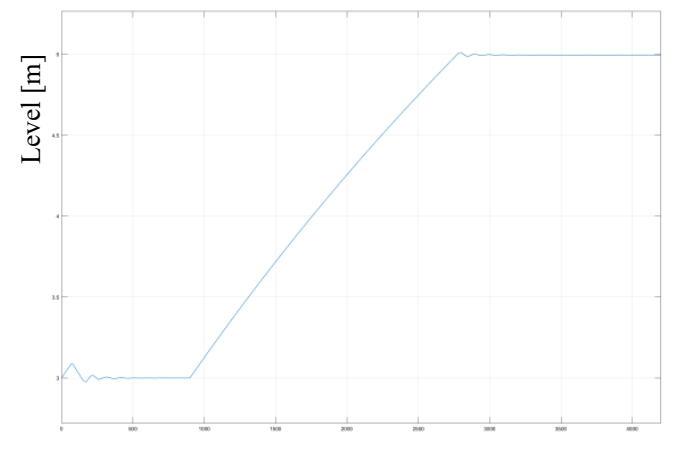

Time [sec]

$P$ controller

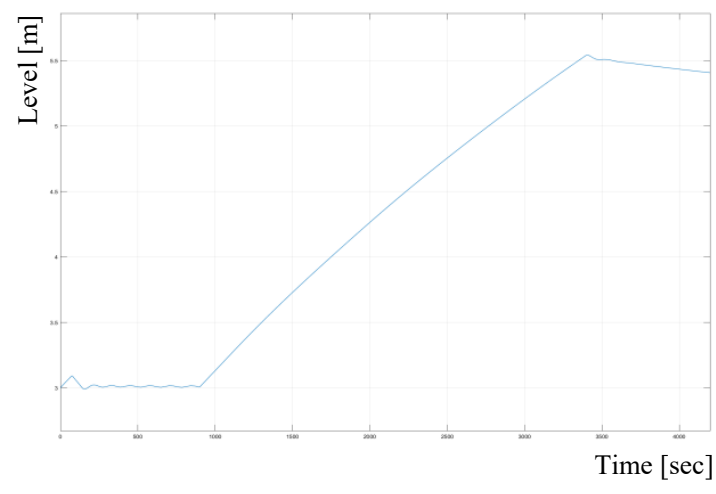

$P I$ controller 


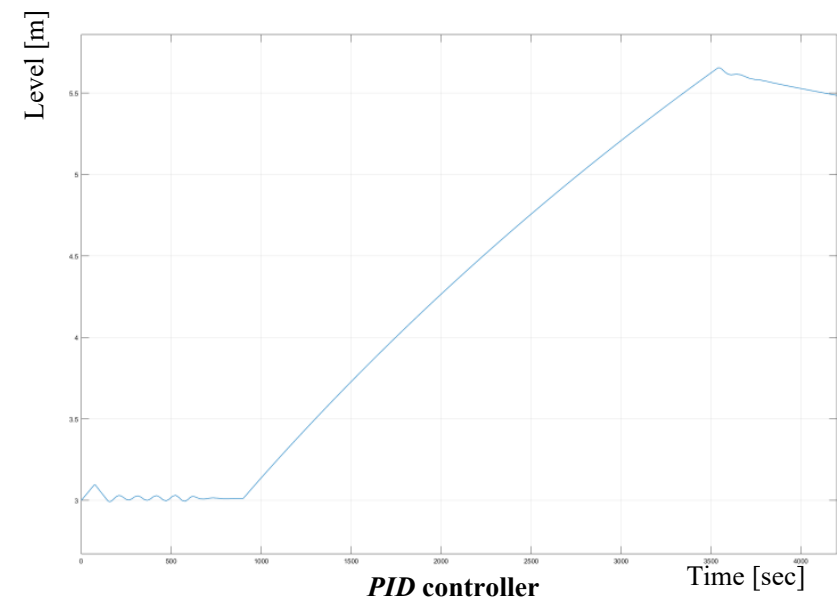

a.
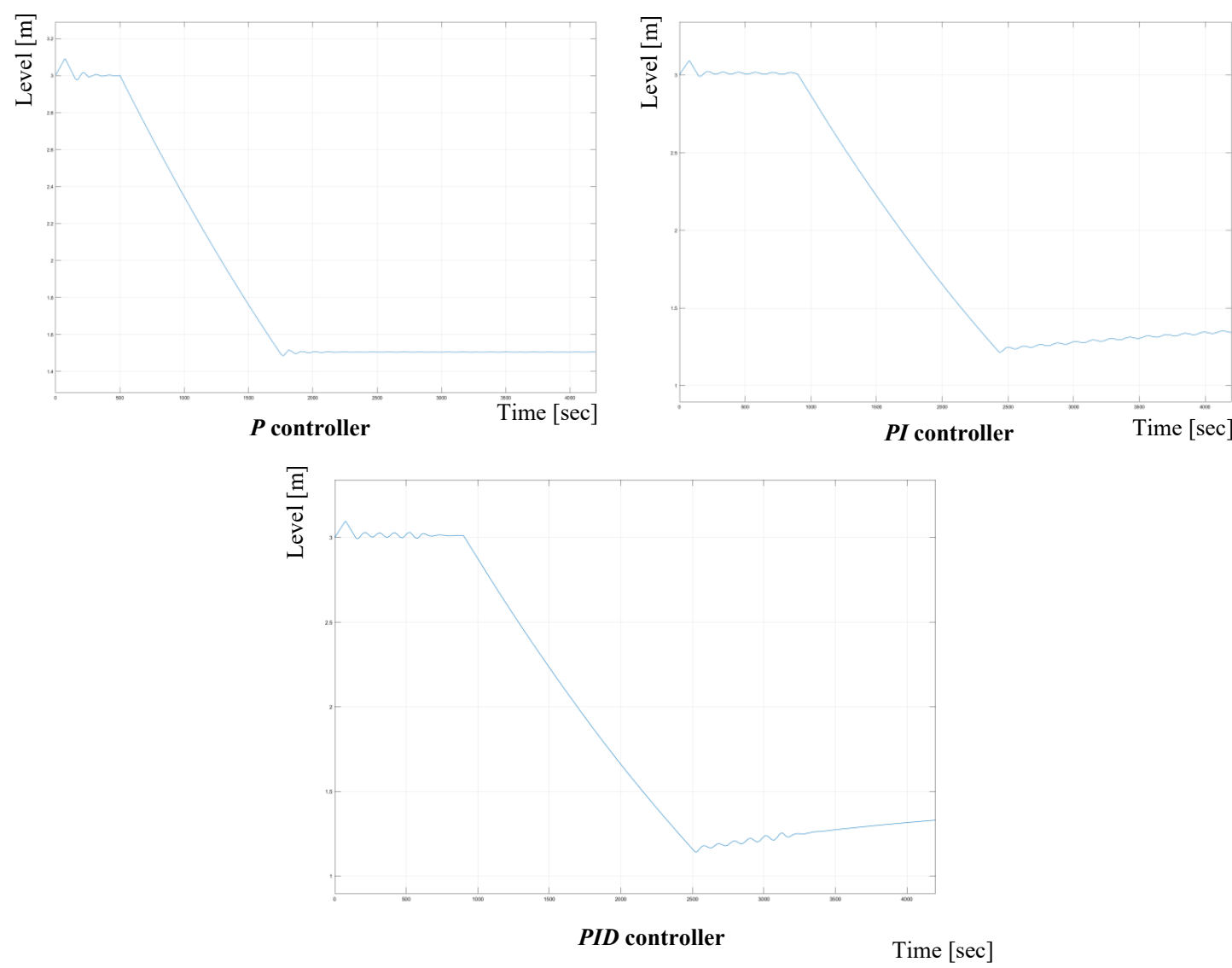

b.

Figure 5: The behavior of the level control process for $P, P I$ and $P I D$ controllers with the step perturbation of level at 900 seconds: $a$. form $3 \mathrm{~m}$ to $5 \mathrm{~m}$ and $\mathrm{b}$. form $3 \mathrm{~m}$ to

\section{$1.5 \mathrm{~m}$}

As it could be noticed from the figure 5, the most stabile control of the level process is with $P$ controller because when the integral component is introduced, a plus of instability is added. As well, considering the PID controller, all controller parameters are a little enhanced to counterbalance the 
"laziness" of the process but, the level control in a reservoir isn't a "lazy" process, it hasn't a great inertia.

The above described method became in the last years, in the technical universities from Romania, a good practices in teaching process control in engineering. By simulation-based learning students can construct more easily and quickly a virtual technological system with the feed-back loop control corresponds to a real one. In this way the physical realisation of a micro-plant of the technological system that take more time is possible to be eliminated. As well, for the students from food engineering the simulation-based learning become a way to design the virtual technological system, to simulate more situations as are the extreme situations concerning the parameters' setting of the controller, the controller structure. Food safety and its quality is a primary field in European and global policy and legislation of the 21 st century because it concerns the required conditions for a healthy population. The key issues for improving the biochemical and micro biochemical safety and the quality of food resides in to understand not only the bioprocess from food technology, but also the way the process can be made operational in real time and economically efficient.

\section{CONCLUSIONS}

This paper describes an implementation of simulation-based learning method in teaching the process control in food engineering higher education. Three laboratories have deal with the construction and simulation of the level control process. It has been constructed a mathematical model for the level dynamic variation of a reservoir and the students, grouped in three teams, realised the feedback system of the reservoir's level in MATLAB-Simulink. The Ziegler-Nichols' method has been used for tuning the controller's parameters. At the end, the students' teams discussed and analysed the results.

The method used in a process control laboratory highlighted that the students achieved the following pedagogical objectives:

a. they developed competence toward "thinking like a scientist";

b. they developed argumentation and critical decision-making skills;

c. they reinforced research-planning and experimental design skills.

Furthermore, the present paper may serve as a simple guide to developing other laboratory practices based on process control in food industry.

\section{REFERENCES}

Agachi, P.S., \& Cristea, M.V. (2014). Basic process engineering control. De Gruyter, 305-306.

Belton, D.J. (2016).Teaching process simulation usingvideo-enhanced and discovery/inquiry-based learning: Methodology and analysis within atheoretical framework for skill acquisition. Education for chemical engineers, 17, 54-64.

Jordão, A.M., \& Cosme, F. (2018). Grapes and wines - Advances in production, processing, analysis and valorization (Sipos, A. Chapter 8: Current state and perspective in the models applicable to oenology). INTECH, 143-169.

Kaiser, I., Mayer, J., \& Malai, D. (2018). Self-generation in the context of inquiry-based learning. Frontiers in Phsychology, 9, 1-16.

Kennedy, T., \& Odell, M. (2014). Engaging students in STEM education. Science Education International, 25(3), 246-258.

Pavlov, C.F., Romankov, P.G., \& Noscov, A.A. (1981). Procese şi aparate în ingineria chimică. Editura Tehnică, Bucureşti.

Sevgi, A.G., Aysegul T.C., Elif, S.K., \& Betul, E.K. (2018). The influence of a design-based elective STEM course on pre-service chemistry teachers' content knowledge, STEM conceptions, and engineering views. Chemical Education Research and Practice, 19, 924-972. 